\title{
$\$$ Research Square

\section{Global Disparities of Greenhouse Gases Emission in Agriculture Sector: Panel Club Convergence Analysis}

Vaseem Akram ( $\square$ akramvaseem001@gmail.com )

Indian Institute of Management Jammu

Jabir Ali

Indian Institute of Management Jammu

\section{Research Article}

Keywords: GHGs emissions, Club convergence/clustering, Agriculture, Cross-country

Posted Date: May 25th, 2021

DOI: https://doi.org/10.21203/rs.3.rs-479200/v1

License: (c) (i) This work is licensed under a Creative Commons Attribution 4.0 International License.

Read Full License 
Vaseem Akram ${ }^{\mathrm{a}^{*}}$ and Jabir Ali ${ }^{* *}$

Abstract

5 A lot has been discussed about the greenhouse gases (GHGs) emissions in the existing studies, the study on the club 6 convergence of GHGs emissions is limited particularly for the agriculture sector. This study tries to investigate the

7 convergence hypothesis across 93 countries spanning 1980-2017. To examine the convergence hypothesis, we 8 implement the novel Phillips and Sul test. Results obtained from this test show the evidence of divergence when we 9 consider all 93 countries as a group. This implies that GHGs across the countries are following different convergence 10 paths. To capture this, we further apply clustering algorithms and results show the existence of five clubs of 11 convergence and one group stating the need for altered the polices at the club level to achieve a single steady-state in 12 GHGs emission. Moreover, our findings recommend that the mitigation policies would be considered the presence of 13 different clubs of regions with different convergence paths in terms of GHGs emissions and account for the 14 distributional effect of transfers across countries.

JEL: O13, O47

aEconomics \& Business Environment Area, Indian Institute of Management Jammu, Old University Campus, Canal Road Nawabad, Cantonment, Jammu, Jammu and Kashmir 180016. "Corresponding author email id: akramvaseem001@gmail.com. ${ }^{* *}$ Email id: jabirali@iimj.ac.in

22 


\section{Introduction}

In recent years, an increase in greenhouse gases (GHGs) emission a major concerned among policymakers and researchers across the countries (Ivanovski and Churchill, 2020). As a result, policymakers are dedicated to implement such policies which reduce the GHGs emission as per the United Nations Framework Convention on Climate Change (UNFCCC). Further, an array of new schemes and reduction targets of GHGs emission are added at the global level during the Kyoto Protocol and it is continuing and trending until now to target the emission level (Friedlingstein et al., 2014; Cui al., 2014; Ivanovski and Churchill, 2020). Notwithstanding of these schemes and reduction-targets, GHGs remain high when it supposed to be low. At a global level, it is noted that over 36 billion tonnes of $\mathrm{CO} 2$ emission produced per year (Olivier and Peters, 2020; Ritchie and Roser, 2019). While looking at the agriculture sector, it is observed that agriculture, forestry and land use accounts for 18.4\% of GHGs emissions in 2020 (Ritchie and Roser, 2019). In other words, agriculture is found to be a substantial contributor to climate change. Both crop and lives stock activities contribute around 5 billion metric tonnes of $\mathrm{CO} 2$ to the atmosphere each year. Similarly, land use in agriculture releases a similar amount per year. Emission from the agriculture and allied sector in total signifies one-fourth of the total from all economic activities (Tubiello, 2019).

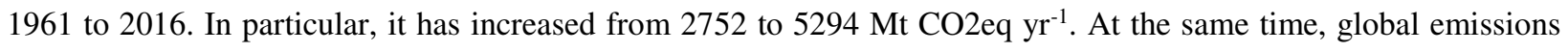
kept increasing. In Table 1 and Figure 1, we produce the GHGs emission decade wise. From Table 1 and Figure 1, we noticed that the world, AI and NAI follows a different pattern in terms of GHGs over the decades.

\section{Insert Table 1}

Moreover, while looking it at a regional level, such amount is much higher particularly in developing countries where total agriculture emissions is more than half of total emissions (Tubiello, 2019). For instance, according to FAOSTAT database in 2017, the trend of emission in developed (AI) countries was increasing until the 1980s and it has started declining after 1980s.

\section{Insert Figure 1}

\section{Insert Figure 2}

On the contrary, in the case of developing (NAI) countries has an increasing trend and it is approximately doubled since the 1960s. The major key component of GHGs emission in the agriculture sector is chemical fertilizers, Co2, methane and, nitrous oxide. Further, In Figure 2, we display the average decadal GHGs of different regains to Global GHGs emissions in percentage. It is noted that Asia continent holds the first positions in contributing to the global

62 GHGs during the 1960s (around 35\%) and 2010s (43\%). Whereas the Americas continent holds the second position

63 in terms of contributing to world GHGs during the 1960s and 2010s. Europe and Oceania both are the lowest 64 contributors to the global GHGs, particularly in recent decades. All the above graphs and Table reflect the regional 65 disparities in terms of GHGs emission in the agriculture sector, even it is more severe at the country level (Kearney, 66 2010). 
Overall, it can be concluded that both the increasing importance of agriculture and environmental consequence on the world stage, a huge disparity in GHGs emission has been noticed across the countries ${ }^{1}$ which motivates us to capture the heterogeneity of GHGs emission in the agriculture sector across the 93 countries for the period 1980-2017 by employing the convergence hypothesis. Examining the convergence hypothesis of GHGs emissions at the country level is plays an important role in climate change protection policies (Ghassen El-Montasser et al. 2015). The convergence hypothesis is primarily driven from the concept of prediction of the environmental Kuznets curve (EKC) hypothesis which is propounded by Brock and Taylor $(2003 ; 2010)$. Three reasons have been explicitly mentioned in the literature in favour of why countries converge in emission (or environmental values): First, gross domestic product (GDP) growth worsens the environmental quality at the initial stage (Ulucak and Apergis, 2018). In the final stage (when GDP growth reaches at threshold), it enhances the environmental quality and leads to a reduction in emission level (Brock and Taylor, 2003). Moreover, rising in GDP per capita leads to reduce the disparities in emissions level across the countries. We called it "convergence" based on the EKC hypothesis (Strazicich and List, 2003). Second, the convergence hypothesis is also "based on the global mitigation policies to halt global warming and climate change as per the guidelines of Intergovernmental Panel on Climate Change, (IPCC), and international agreements, like Kyoto Protocol (Aldy, 2006)". An increase/decrease disparity in the GHGs emissions across the countries affect the design and implementation of mitigation policies and the principles used to share the burden of emission reduction. Apergis et al. (2017) state that if the disparities in GHGs emissions decline (when their overall growth dampens), the distributional impact of the mitigation policies will be less concerning for the policymakers because transfers are reduced across the countries as they converge (Burnett 2016; Apergis and Garzón, 2020). On the contrary, "if differences increase in GHGs emissions, mitigation policies might have distributional cost across countries implying increasing transfers or reallocation of emission-intensive agriculture sector". Thus, authorities should consider the nations' emissions disparities while designing the mitigation policies (Burnett 2016; Apergis and Payne 2017). Third, slower GDP growth is connected initial of pollution, intensity or concentrations emissions (Stern, 2015).

Bulk of the studies examined the "environmental convergence focusing on the ecological footprint (EF) or carbon emissions CO2 or GHGs at the aggregate level" (See, Strazicich and List, 2003; Westerlund and Basher, 2008; Lee and Chang, 2009; Barassi et al., 2011; Acar and Lindmark, 2017; Apergis and Payne, 2017; Bilgili and Ulucak 2018; Rios and Gianmoena, 2018; Bilgili et al., 2019; Ulucak and Apergis, 2018; Haider and Akram, 2019a, 2019b; Ulucak et al., 2019; Churchill et al. 2018, 2020; Ivanovski and Churchill, 2020; Ulucak et al., 2020; Apergis and Garzón, 2020; Bhattacharya et al., 2020; Haider, et al. 2021; among others). However, the study on the GHGs emissions convergence for the agriculture sector across a large set of countries is limited.

Hence, the present study bridges the above research gap and adds existing studies. In the previous literature, GHGs emissions in the agriculture sector is less discussed. In particular, we contribute to the Ivanovski and Churchill, (2020) and Apergis and Garzón, (2020) into three-folds. First, Ivanovski and Churchill, (2020) examine the GHGs emissions convergence in case Australia over the period 1990 to 2017 and their findings show evidence of

${ }^{1}$ Kindly see the FAOSTAT database. 
convergence. While, Apergis and Garzón, (2020) studied the same hypothesis for Spain for the period 1990 to 2017. They conclude the evidence of convergence. Apergis and Garzón, (2020) and Ivanovski and Churchill, (2020) do not study the GHGs emission convergence across the countries rather their emphasis was on the individual country at the sub-national level. In our study, we consider a total of 93 countries for broader policy insights. Second, both the studies (Apergis and Garzón, 2020; Ivanovski and Churchill, 2020) examined the GHGs emission convergence by taking the total GHGs at the sub-national level. In our study, we take the agricultural GHGs emissions which is still unexplored in the existing literature. Studying the environmental convergence of the agriculture sector is vital because it is one of the major contributors to the global GHGs emissions level (Tubiello, 2019) as discussed above. Also, a huge disparity is observed across countries in terms of agriculture's GHGs emissions. As a result, this might affect nations mitigation polices. Thus, "it may be expected that countries with lower initial GHGs might show faster GHGs emissions". Third, we considered the GHGs emissions as a percentage of valued added in the agriculture sector unlike Apergis and Garzón, (2020) and Ivanovski and Churchill, (2020) because measuring the GHGs emission in per unit value-added gives better information of the agriculture sector and evades the issue of double-counting (Randers, 2012). Thus, differs from the existing studies in terms of measuring the GHGs emissions in the agriculture sector.

We use the novel club convergence notion advance by Philips and Sul $(2007,2009)$ to attain the objectives of this study. In other words, this study does not rely on the neoclassical single steady state-growth model (See, Solow, 1956) which indicates that "lower initial growth countries grow rapidly and meet to the developed countries. This is known as the $\beta$-convergence approach (Haider, et al. 2021). Empirically, if $\beta$ is found to be negative and significant, one can suggest evidence of convergence. Moreover, countries that have lesser capital, grow faster than the countries which are rich in the capital (Barro and Sala-i-Martin, 1992). Whereas, conditional convergence suggests that "convergence will be conditioned on country-specific heterogeneous factors like an endowment, technological progress, population growth, saving rate, etc". Overall, a single study is assumed by the classical theories where countries converge to a single equilibrium. However, this may not be the case in the real world, where countries growth is uniform (Ulucak and Apergis, 2018; Apergis, 2018) rather they might have specific or unique transition paths (See, Durlauf and Johnson, 1995; Phillips and Sul, 2007). Thus, our paper account for the disparate nature of countries as a "wide range of recent studies mentions that countries differ in technology and resources to improve environmental quality" which lead to differences in the transition paths.

The remainder of the paper is as follows: Section 2 describes the methodology and data description; Section 3 illustrates the empirical results and the final section concludes.

\section{Methodology and data description}

\subsection{Convergence Approach by Phillips and Sul (2007; 2009, hereafter PS)}

133 In order to achieve the goal of the paper, this study uses the PS to identify the transition path and speed of convergence 134 across the selected countries. This methodology is based on the clustering algorithm that identifies the club 135 endogenously. This test is widely implemented in the energy and emissions literature. This test is distinct in a way 
that it provides multiple equilibria by accounting for the heterogeneity across the countries (Tian, Zhang, Zhou and $\mathrm{Yu}, 2016)$

Begin with a single factor equation of $G H G s_{i t}$, where $i$ signifies the nations and $t$ embodies the time.

$$
G H G s_{i t}=\delta_{i} \vartheta_{t}+\varepsilon_{i t}
$$

Where $\delta_{i}$ is evaluating the idiosyncratic distance between some common factor $\vartheta_{t}$ and the systematic part of $Y_{i t}$. Here, influence on the country (individual) behaviour. $\varepsilon_{i t}$ is the error term in the model.

To make the above model a time-varying representation of factors, a random factor $\delta_{i t}$ is added which absorbs the $\varepsilon_{i t}$ and at the same time highlights the possible convergence behaviour of $\delta_{i t}$ in relation to common factor $\left(\vartheta_{t}\right)$ across the time. The new model is:

$$
G H G s_{i t}=\delta_{i t} \vartheta_{t}
$$

The panel decomposition will include common $\left(A_{i t}\right)$ and idiosyncratic $\left(B_{i t}\right)$ components as:

$$
G H G s_{i t}=A_{i t}+B_{i t}
$$

149 The common and idiosyncratic components in the model are separated by multiplying and dividing the above model with a common factor $\left(\vartheta_{t}\right)$

$$
G H G s_{i t}=\left(\frac{A_{i t}+B_{i t}}{\vartheta_{t}}\right) \vartheta_{t}=\delta_{i t} \vartheta_{t} \quad \forall i, t
$$

Though $\delta_{i t}$ is indicating a time-varying idiosyncratic element, but it also measures the relative share of individuals at different-different time periods. In other words, $\delta_{i t}$ indicates heterogeneous and time-varying transition paths of individuals. The long-run convergence in two series can be there if their factor loadings converge $\left(\delta_{i t} \rightarrow \delta\right)$. The common factor $\left(\vartheta_{t}\right)$ can be removed through the rescaling to the panel average.

Here, $h_{i t}$ draws the transition path of a particular economy in relation to the panel average. To construct the algorithm of club convergence, the following assumption is required:

$$
h_{i t}=\left(\frac{G H G s_{i t}}{\frac{1}{N} \sum_{i=1}^{N} G H G s_{i t}}\right)=\left(\frac{\delta_{i t}}{\frac{1}{N} \sum_{i=1}^{N} \delta_{i t}}\right)
$$

$$
\gamma_{i t}=\gamma_{i}+\sigma_{i t} \xi_{i t}
$$

Where $\sigma_{i t}=\frac{\sigma_{i}}{L(t) t^{2}}, \sigma_{i}>0, t \geq 0$ and $\xi_{i t}$ weakly dependent over $t$, and independent identically distributed (iid) $(0,1)$ over $i$. The $\log (\mathrm{t})$ function varies steadily and increasing and diverging to the at infinity. Further, PS has suggested the null and alternative hypothesis of $\gamma_{i t}$ for all $i$ as follows:

$$
\text { Null hypothesis, } H_{0}: \gamma_{i}=\gamma, \quad a>0
$$


As per this methodology, the null hypothesis of convergence can be rejected if the calculated value is less than the critical value (-1.65). Phillips and Sul (2007) call the one-sided $t$-test, which is based on $t_{\hat{b}}$, the $\log t$-test due to the presence of the $\log (t)$ repressor in Equation (7).

PS has suggested the following regression model to test the null of convergence.

$$
\log \left(\frac{H_{1}}{H_{t}}\right)-2 \log L(t)=\hat{c}+\hat{b} \log t+\hat{u}_{t}
$$

Here, $t=[r T],[r T]+1, \ldots \ldots, T$ and $r>0 ; H_{t}=\frac{1}{N} \sum_{i=1}^{N}\left(h_{i t}-1\right)^{2}$ and $\hat{b}=2 \hat{a} . \hat{a}$ refers to the least square parameter 173 of $a$. In the case of null hypothesis, the $Y_{i t}$ diverge when $a>0$ or $a=0$. In this case, convergence can be tested by $t$-test 174 of the inequality, $a>0$. The $t$-test statistic follows the standard normal distribution asymptotically and is constructed using heteroscedasticity and autocorrelation. We select the $r=0.33$ based on the recommendation of PS $^{2}$.

\subsection{Data description}

177 This study uses the GHGs dataset for 93 countries which are extracted from the Food and Agriculture Organization 178 Corporate Statistical Database (FAOSTAT) for the period 1980 to 2017. The selection of the sample of the countries and period is selected based on the data availability. Agriculture, forestry, and fishing, value added (at constant 2010 US\$) is collected from the World Bank Indicator (WDI) published world bank. GHGs kg emission is measured in per unit value added to measure the correct agriculture size.

\section{Empirical results}

This section starts with an opening analysis based on mean, standard deviation, maximum, and minimum for an aggregate panel consisting of 93 countries and club-wise. The results reported in Table 2 show that the mean value of GHGs kilograms $(\mathrm{kg})$ in per unit of value-added of the aggregate panel is found to be 3.53 kilogram per unit valueadded. While looking at the mean of GHGs club wise, we notice that Club 1 countries have the highest mean GHGs emissions compared to Clubs 2, 3, 4 and 5. The reason for high GHGs emissions for Club 1 because it consists of the majority of African and some American countries where GHGs emissions is found to be major concerns as mentioned by FAO, (2020) report. While in the case of Club 6, we note lowest mean GHGs emission in per unit value added because this club includes two countries which have low-level GHGs emission. Further from standard deviation, it is found that Club 1 countries are highly volatile whereas Club 5 countries less volatile. Similarly, a gap between is more widen in the case of Club 1. A low gap is noticed in Club 6.

\section{Insert Table 2}

Overall, from summary statistics, we noticed that each club has a distinct mean value of GHGs emissions. countries converge to an equilibrium (See, Durlauf and Johnson, 1995; Phillips and Sul, 2007). Thus, this study next

${ }^{2}$ Detailed steps of convergence test can be found in Phillips and Sul (2007; 2009). 
use Phillips and Sul, (2007) test to check the convergence hypothesis. The results of Phillips and Sul, (2007) is reported in Table 3. Column 2 labels the list of countries in clubs. Column 3 includes estimated coefficients $(\hat{b})$ of each clubs and column 4 provides the calculated $\log (t)$ values based on that one rejects the null of convergence. Final column labels the decision on the null of convergence. Results indicate no evidence of convergence for the aggregate panel because calculated value $\log \left(t_{\hat{b}}\right)=-14.36$ is lesser than critical value $\log \left(t_{b}\right)=-1.65$. Thus, we reject the null of convergence implying no evidence of single steady states. This further suggests using the clustering algorithms to find evidence of multiple equilibria. Results show the existence of eight clubs that are converging to their own steady-state and one group.

\section{Insert Table 3}

\section{Insert Table 4}

207

As suggested by PS that clustering technique may outperform and create a greater number of clubs than a true number because the formation of clubs is based on sign criteria. To resolve this problem, the clustering algorithm is reapplied between adjacent club. Findings reported in Table 4 show the evidence Club 2 is merging with Club 3, Club 3 is merging with Club 4 and Club 4 is merging with Club 5. After identifying the mergence between the clubs, we discuss the final clubs in Table 5. Our findings suggest the existence of five final clubs. Club 1 includes Belize, Bolivia, Botswana, Bulgaria, Burkina Faso, Burundi, Congo, Cuba, El Salvador, Fiji, Gambia, Iraq, Kenya, Lesotho, Malawi, Mali, Mauritania, Mongolia, Namibia, Nicaragua, Pakistan, Senegal, Sierra Leone, Singapore, Togo, Trinidad and Tobago, Uganda, Zambia, and Zimbabwe. In other words, it includes African and some American countries where GHGs emissions is found to be major concerns as mentioned by FAO, (2020) report. Club 2 includes Argentina, Australia, Bangladesh, Benin, Bhutan, Brazil, Cameroon, Colombia, Cyprus, Denmark, Dominican Republic, Eswatini, France, Gabon, Guatemala, Guyana, Honduras, India, Indonesia, Mexico, Mozambique, Nepal, New Zealand, Panama, Peru, Philippines, Rwanda, Saint Lucia, South Africa, Thailand, and Tonga. These set of countries have low GHGs emissions in per value-added compared to Club 1's countries. Likewise, Clubs 3, 4 and 5 have relatively low GHGs emissions level in per value-added.

\section{Insert Table 5}

For better understanding, we plot the transition paths along with the stability line for each club over the years in Figure 3. It is visualized from Figure 3 that Cub 1' countries following an increasing trend and it lies above the stability line (i.e., black line). Whereas the rest of the club following a decreasing trend and below the stability line. These findings suggest that Club 1's countries can adopt the policies and programme of Club 2, 3, 4 and 5 related GHGs reduction of the agricultural sector. Moreover, our findings suggest that the mitigation policies would be considered the presence of different clubs of regions with different convergence paths in terms of GHGs emissions and account for the distributional effect of transfers across countries. Moreover, a common policy may not be appropriate to reduce the GHGs emissions in the agriculture sector across the countries. Our findings can be compared with many existing studies such as (Apergis and Payne, 2017; Ivanovski and Churchill, 2020).

\section{Insert Figure 3}




\section{Conclusions}

235

This study addressed a vital issue of the environment by emphasizing on the GHGs emissions of the agriculture sector. In particular, we studied the convergence hypotheses of GHGs in per unit value added across 93 countries for the period 1980 to 2017. We employed Philips and Sul panel club convergence test to achieve the goal of the study. The results derived from the Philips and Sul panel club convergence showed the existence of five final clubs. Each of the club following different transition paths or converging to their own steady states. This suggests that the neoclassical framework of a single steady is invalid in this case.

Our findings suggest the following policies: (i) The agriculture of policies GHGs may follow the distinctive convergence paths for each club. Further, it can be suggested to the policymakers of Clubs 1, 2, 3, and 4 countries may follow the agricultural-related policies of Club 5 countries where GHGs emission found to be relatively low. In other words, our findings suggest that poor and developing countries should introduce suitable policies and may follow the successful policies (related to cleaner-energy) of those countries (Club 5 countries) that have low GHGs emissions; (ii) GHGs in the agriculture sector might be reduced by following the following strategies: Improving the efficiency of this sector, innovation and technological advancement in agriculture sector may further help to reduces the GHGs emissions, reducing deforestation; utilizing alternative cleaner sources of energy in the agriculture sector by providing subsidies, etc. (Solorin et al. 2019; Haider, et al. 2021); (iii) Poverty seems to be one of the issues in lower- and middle-income countries that put at risk the process of sustainable development. The use of low-cost energy production technology in the agriculture sector appears to be a viable solution in the reduction of GHGs emissions.

\section{Declaration}

1. Ethics approval and consent to participate: Not applicable

2. Consent for publication: Not applicable

3. Availability of data and materials: Available upon request

4. Competing interests: The authors declare that they have no competing interests

5. Funding: Not applicable

6. Authors' contributions: Vaseem Akram conducted data analysis and literature review and Jabir Ali prepares the final draft of the paper.

7. Dataset Citation

GHGs emissions, FAOSTAT, Food and agriculture organization corporate statistical database (FAOSTAT). http://www.fao.org/faostat/en/\#data

Agriculture, forestry, and fishing, value added (at constant 2010 US\$), Word Development Indicators (WDI), https://databank.worldbank.org/source/world-development-indicators. 
References

267

Acar, Sevil, and Magnus Lindmark. 2016. Periods of converging carbon dioxide emissions from oil combustion in a Pre-Kyoto context. Environmental Development, 19, 1-9.

Aldy, J.E. 2006. Per capita carbon dioxide emissions: Convergence or divergence? Environmental \& Resource Economics, 33, 533-55.

Apergis, N, Payne, J., E. 2017. Per capita carbon dioxide emissions across US states by sector and fossil fuel source: evidence from club convergence tests. Energy Economics, 63(2)365-372.

Apergis, N., Garzón, A.J. 2020. Greenhouse gas emissions convergence in Spain: evidence from the club clustering approach. Environmental Science and Pollution Research, 27, 38602-38606.

Apergis, N., Payne J.E, Topcu M., 2017. Some empirics on the convergence of carbon dioxide emissions intensity across US states. Energy Sources, Part B: Economics, Planning, and Policy, 12(9), 831-837.

Barassi, M.R., Cole, M.A., Elliott, R.J., 2011. The stochastic convergence of CO2 emissions: A long memory approach. Environmental and Resource Economics, 49 (3), 367-385.

Barro, R., J., Sala-i-Martin, X. 1992. Convergence. Journal of Political Economy, 100(2), 223-51.

Bhattacharya, M., Inekwe, J.N., Sadorsky, P., 2020a. Consumption-based and territory based carbon emissions intensity: Determinants and forecasting using club convergence across countries. Energy Economics. 86, 104632.

Bilgili, F., Ulucak, R. 2018. Is there deterministic, stochastic, and/or club convergence in ecological footprint indicator among G20 countries? Environmental Science and Pollution Research, 25, 35404-35419.

Bilgili, F., Ulucak, R., \& Koçak, E. (2019). Implications of environmental convergence: Continental evidence based on ecological footprint. In Energy and environmental strategies in the era of globalization (pp. 133-165). Springer, Cham.https://link.springer.com/chapter/10.1007/978-3-030-06001-56.

Brock, W. A., M. Scott Taylor. 2003. The kindergarten rule of sustainable growth. Working Paper 9597. NBER. Massachusetts. —. 2010. The green Solow model. Journal of Economic Growth 15 (2). Springer US: 127-53. doi:10.1007/s10887-010-9051-0.

Burnett, J.W. 2016. Club convergence and clustering of US energy-related CO2 emissions. Resource and Energy Economics, 46, 62-84.

Churchill, A., Inekwe, S., Ivanovski, J.K., 2018. Conditional convergence in per capita carbon emissions since 1900. Applied Energy 228, 916-927. https://doi.org/ 10.1016/j.apenergy.2018.06.132.

Churchill, A., S., Inekwe, J., Ivanovski, K., 2020. Stochastic convergence in per capita CO2 emissions: evidence from emerging economies, 1921-2014. Energy Econ. 86, 104659. https://doi.org/10.1016/j.eneco.2019.104659. 
Cui, L.-B., Fan, Y., Zhu, L., Bi, Q.-H., 2014. How will the emissions trading scheme save cost for achieving China's 2020 carbon intensity reduction target? Applied Energy, 136, 1043-1052.

Durlauf, Steven N., and Paul A. Johnson. 1995. "Multiple Regimes and Cross-Country Growth Behaviour." Journal of Applied Econometrics 10 (4). Wiley Subscription Services, Inc., A Wiley Company: 365-84. doi:10.1002/jae.3950100404.

FAOSTAT. Food and agriculture organization corporate statistical database (FAOSTAT). http://www.fao.org/faostat/en/\#data

FAO, 2018. FAOSTAT Database. http://www.fao.org/faostat/en/\#data

Friedlingstein, P., Andrew, R.M., Rogelj, J., Peters, G., Canadell, J.G., Knutti, R., ... van Vuuren, D.P., 2014. Persistent growth of $\mathrm{CO} 2$ emissions and implications for reaching climate targets. Nature geoscience, 7 (10), 709-715.

Ghassen El-Montasser, Inglesi-Lotz, R., Gupta, R., 2015. Convergence of greenhouse gas emissions among G7 countries. Applied Economics, 47, 60, 6543-6552.

Haider, S., Akram, V. \& Ali, J. Does biomass material footprint converge? Evidence from club convergence analysis. Environ Sci Pollut Res (2021). https://doi.org/10.1007/s11356-021-12464-1.

Haider, Salman, and Vaseem Akram. 2019a. "Club Convergence Analysis of Ecological and Carbon Footprint: Evidence from a Cross-Country Analysis." Carbon Management 10(5), 451-63.

Haider, Salman, and Vaseem Akram. 2019b. Club convergence of per capita carbon emission: global insight from disaggregated level data. Environmental Science and Pollution Research 26(11), 11074-86.

Ivanovski, K., Churchill, S.A. 2019. Convergence and determinants of greenhouse gas emissions in Australia: A regional analysis. Energy Economics, 92,104971.

Kearney, J., 2010. Food consumption trends and drivers. Philosophical Transactions of the Royal Society B 365, 2793-2807.

Lee, C. C., Chang, C.P., 2008. New evidence on the convergence of per capita carbon dioxide emissions from panel seemingly unrelated regressions Augmented Dickey Fuller tests. Energy, 33 (9), 1468-75.

Olivier, J.G., Peters, J., 2020. Trends in Global CO2 and Total Greenhouse Gas Emissions: 2019 Report. vol. 5. PBL Netherlands Environmental Assessment Agency, The Hague.

Phillips, P.C., Sul, D., 2007. Transition modeling and econometric convergence tests. Econometrica, 75 (6), $1771-$ 1855.

Phillips, P.C., Sul, D., 2009. Economic transition and growth. Journal of Applied Econometrics, 24 (7), 1153-1185.

Randers, S. 2012. Greenhouse gas emissions per unit of value added ("GEVA") — A corporate guide to voluntary climate action. Energy Policy, 48, 46-55. 
Rios, V., Gianmoena, L., 2018. Convergence in CO2 emissions: A spatial economic analysis with cross-country interactions. Energy Economics, 75, 222-238.

Ritchie, H., Roser, M., 2019. $\mathrm{CO}_{2}$ and Greenhouse Gas Emissions. Our World in Data, Oxford.

Solarin, Sakiru Adebola. 2019. "Convergence in CO2emissions, Carbon Footprint and Ecological Footprint: Evidence from OECD Countries.” Environmental Science and Pollution Research. doi: 10.1007/s11356-018-3993-8.

Solow, R., M. 1956. A contribution to the theory of economic growth. Source: The Quarterly Journal of Economics 70 (1). The MIT Press: 65-94. http://www.jstor.org/stable/1884513.

Stern, David I. 2015. The Environmental Kuznets Curve after 25 Years. 1514. CCEP Working Paper. Crawford. https://ccep.crawford.anu.edu.au/sites/default/files/publication/ccep_crawford_anu_edu_au/201601/ccep1514_0.pdf.

Strazicich, M.C., John A., List. 2003. Are CO2 emission levels converging among industrial countries? Environmental and Resource Economics 24(3). Kluwer Academic Publishers: 263-71. doi:10.1023/A:1022910701857.

Tian, Xu, Zhang, Xiaoheng, Zhou, Yingheng and Yu, Xiaohua, (2016), Regional income inequality in China revisited: A perspective from club convergence, Economic Modelling, 56, issue C, p. 50-58.

Tubiello, F.N., 2019. Greenhouse gas emissions due to agriculture. Reference Module in Food Science Encyclopedia of Food Security and Sustainability, 1, 196-205.

Ulucak, R., Apergis, N. 2018. Does convergence really matter for the environment? An application based on club convergence and on the ecological footprint concept for the EU countries. Environmental Science \& Policy, $80,21-27$.

Ulucak, R., Kassouri, Y., İlkay, S. Ç., Altıntaş, H., \& Garang, A. P. M. (2020). Does convergence contribute to reshaping sustainable development policies? Insights from Sub-Saharan Africa. Ecological Indicators, 112, 106140. https://doi.org/10.1016/j.ecolind.2020.106140.

Ulucak, R., Yücel, A. G., \& Koçak, E. (2019). The process of sustainability: From past to present. In Environmental Kuznets Curve (EKC) (pp. 37-53). Academic Press. https://doi.org/10.1016/B978-0-12-816797-7.00005-9.

Westerlund, J., Basher. S.A., 2008. Testing for convergence in carbon dioxide emissions using a century of panel data. Environmental and Resource Economics, 40 (1): 109-20. doi:10.1007/s10640-007-9143-2. 


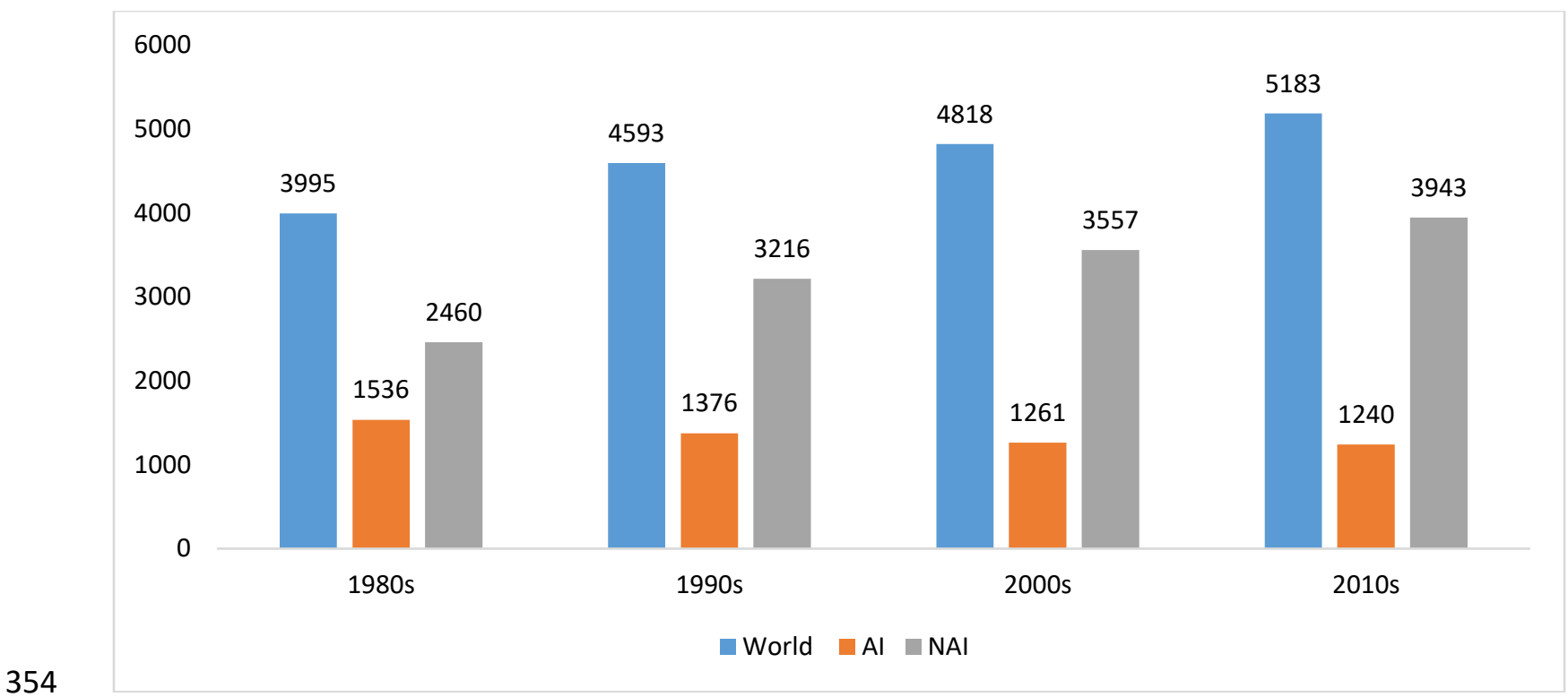

Figure 1: Plot the decadal GHGs emission. Note: Author's plot based on the FAOSTAT database

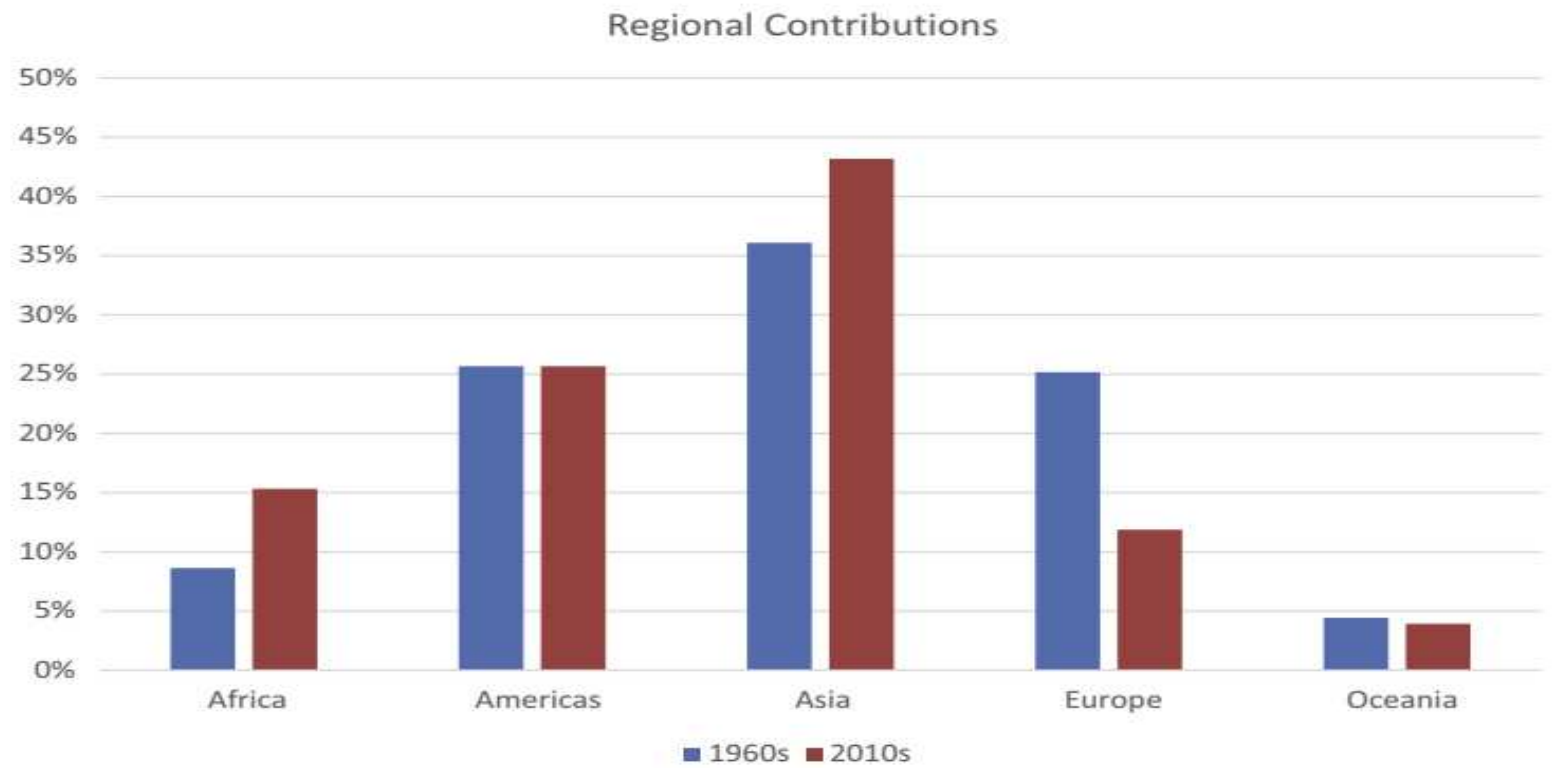

Figure 2: Decadal averages, regarding the period 1961-2016, of the percent (\%) contributions of regional emissions to global GHGs emissions from agriculture, shown for two decades: 1960s and 2010s. Source: FAOSTAT database (FAO, 2018), domain: Emissions-Agriculture. More details of the same can be found in Tubiello, (2019). 

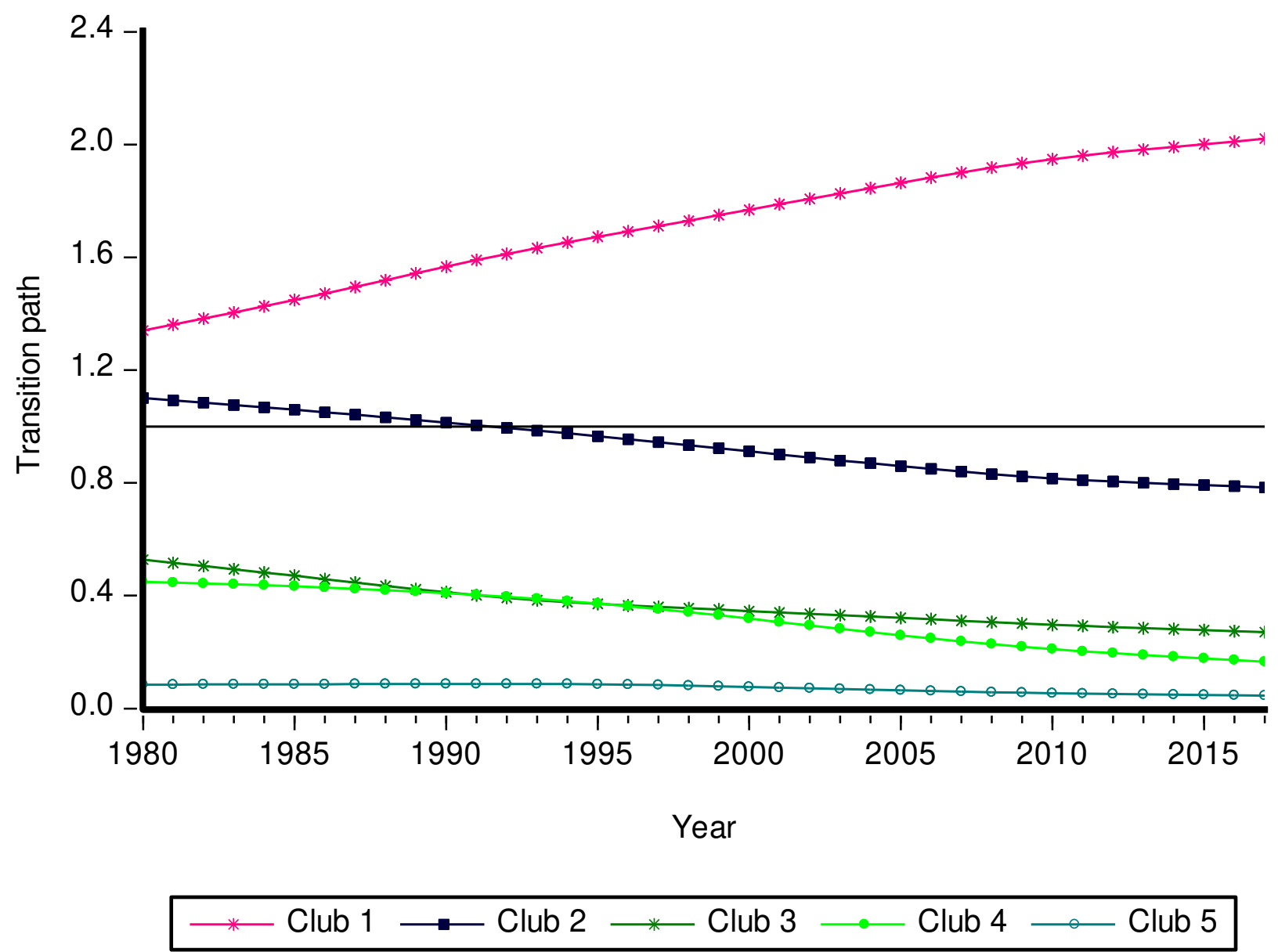

365

Table 1: Mean of total world GHG emission at decadal level (Mt CO2eq $\mathrm{yr}^{-1}$ )

\begin{tabular}{lllll}
\hline & $1980 \mathrm{~s}$ & $1990 \mathrm{~s}$ & $2000 \mathrm{~s}$ & $2010 \mathrm{~s}$ \\
\hline World & 3995 & 4593 & 4818 & 5183 \\
AI & 1536 & 1376 & 1261 & 1240 \\
NAI & 2460 & 3216 & 3557 & 3943 \\
\hline
\end{tabular}

371 Note: AI=Annex I countries; NAI= Non-annex I countries to the UNFCCC. Source: FAOSTAT database (FAO, 2018), domain: Emissions Agriculture.

Table 2: Summary statistic of GHGs of agriculture sector

\begin{tabular}{llllllll}
\hline Statistics & Full sample & Club 1 & Club 2 & Club 3 & Club 4 & Club 5 & Group \\
\hline Mean & 3.53 & 6.05 & 3.30 & 1.31 & 1.15 & 0.26 & 11.17 \\
Std. & 4.80 & 7.33 & 2.17 & 0.86 & 0.64 & 0.11 & 2.77 \\
Minimum & 0.04 & 0.17 & 0.21 & 0.04 & 0.28 & 0.13 & 6.54 \\
Maximum & 74.66 & 74.66 & 19.18 & 5.62 & 3.75 & 0.55 & 15.32 \\
Observation & 3534 & 1102 & 1178 & 1026 & 114 & 76 & 38 \\
\hline
\end{tabular}

Figure 3: This figure indicates the transition paths of GHG emissions across the clubs. We observed that GHG emission level of Clubs 3, 4 and 5 countries have been decreasing over the years. These countries can be the policy guiding countries for Club 1 countries where GHG emission level is found to be relatively high (or above the stability line).

Note: GHGs kg emission is measured in per unit value added. 
Table 3: Club convergence across the countries

\begin{tabular}{|c|c|c|c|c|}
\hline Clubs & Regions & $\widehat{\boldsymbol{b}}$ & $\log (t)$ & Decision \\
\hline Full Samples & All countries & -0.64 & -14.36 & Divergence \\
\hline Club 1 & $\begin{array}{l}\text { Belize, Bolivia, Botswana, Bulgaria, Burkina Faso, } \\
\text { Burundi, Congo, Cuba, El Salvador, Fiji, Gambia, Iraq, } \\
\text { Kenya, Lesotho, Malawi, Mali, Mauritania, Mongolia, } \\
\text { Namibia, Nicaragua, Pakistan, Senegal, Sierra Leone, } \\
\text { Singapore, Togo, Trinidad and Tobago, Uganda, Zambia, } \\
\text { Zimbabwe }\end{array}$ & -0.08 & -1.24 & Convergence \\
\hline Club 2 & $\begin{array}{l}\text { Argentina, Australia, Brazil, Mozambique, Nepal, New } \\
\text { Zealand, Panama, South Africa }\end{array}$ & 0.61 & 3.80 & Convergence \\
\hline Club 3 & $\begin{array}{l}\text { Bangladesh, Cameroon, Colombia, Denmark, Guatemala, } \\
\text { Guyana, Honduras, Mexico, Rwanda, Thailand }\end{array}$ & 0.51 & 6.62 & Convergence \\
\hline Club 4 & $\begin{array}{l}\text { Cyprus, Dominican Republic, France, India, Peru, } \\
\text { Philippines, Saint Lucia, Tonga, }\end{array}$ & 0.33 & 6.51 & \\
\hline Club 5 & Benin, Bhutan, Eswatini, Gabon, Indonesia & 0.30 & 9.02 & Convergence \\
\hline Club 6 & $\begin{array}{l}\text { Austria, Chile, China, Comoros, Costa Rica, Dominica, } \\
\text { Ecuador, Egypt, Finland, Grenada, Iran (Islamic Republic } \\
\text { of), Jamaica, Jordan, Kiribati, Malaysia, Mauritius, } \\
\text { Morocco, Netherlands, Norway, Republic of Korea, Saint } \\
\text { Kitts and Nevis, Saudi Arabia, Sri Lanka, Suriname, } \\
\text { Sweden, Tunisia, Turkey, }\end{array}$ & 0.03 & 2.89 & Convergence \\
\hline Club 7 & Cabo Verde, Nigeria, Saint Vincent and the Grenadines, & 0.13 & 3.04 & Convergence \\
\hline Club 8 & Seychelles, Switzerland & 3.05 & 4.19 & Convergence \\
\hline Group & Paraguay & --- & --- & Convergence \\
\hline
\end{tabular}

Table 4: Results of merger of club

\begin{tabular}{llll}
\hline Club Mergence & Coefficients & $\log (\mathbf{t})$-stat & Decision \\
\hline Club1+2 & -0.29 & -4.70 & No Merger \\
Club2+3 & $0.24^{* *}$ & 1.90 & Merger \\
Club3+4 & $0.21^{* *}$ & 3.79 & Merger \\
Club4+5 & $0.32^{* *}$ & 7.36 & Merger \\
Club5+6 & -0.12 & -18.73 & No Merger \\
Club6+7 & -0.10 & -9.56 & No Merger \\
Club7+8 & -0.20 & -10.32 & No Merger \\
Group & -0.67 & -277.67 & No Merger \\
\hline
\end{tabular}

Notes: Critical value of PS is -1.65 at $5 \%$ level of the significance level. ${ }^{* *}$ show non-rejection of the null of convergence. The results show evidence of club convergence. 
Table 5: Final club of GHGs

\begin{tabular}{|c|c|c|c|c|}
\hline Clubs & Regions & $\widehat{\boldsymbol{b}}$ & $\log (\mathbf{t})$ & Decision \\
\hline Club 1 & $\begin{array}{l}\text { Belize, Bolivia (Plurinational State of), Botswana, Bulgaria, } \\
\text { Burkina Faso, Burundi, Congo, Cuba, El Salvador, Fiji, } \\
\text { Gambia, Iraq, Kenya, Lesotho, Malawi, Mali, Mauritania, } \\
\text { Mongolia, Namibia, Nicaragua, Pakistan, Senegal, Sierra } \\
\text { Leone, Singapore, Togo, Trinidad and Tobago, Uganda, } \\
\text { Zambia, Zimbabwe }\end{array}$ & -0.08 & -1.24 & Convergence \\
\hline Club 2 & $\begin{array}{l}\text { Argentina, Australia, Bangladesh, Benin, Bhutan, Brazil, } \\
\text { Cameroon, Colombia, Cyprus, Denmark, Dominican Republic, } \\
\text { Eswatini, France, Gabon, Guatemala, Guyana, Honduras, } \\
\text { India, Indonesia, Mexico, Mozambique, Nepal, New Zealand, } \\
\text { Panama, Peru, Philippines, Rwanda, Saint Lucia, South Africa, } \\
\text { Thailand, Tonga }\end{array}$ & 0.02 & 0.19 & \\
\hline Club 3 & $\begin{array}{l}\text { Austria, Chile, China, Comoros, Costa Rica, Dominica, } \\
\text { Ecuador, Egypt, Finland, Grenada, Iran (Islamic Republic of), } \\
\text { Jamaica, Jordan, Kiribati, Malaysia, Mauritius, Morocco, } \\
\text { Netherlands, Norway, Republic of Korea, Saint Kitts and } \\
\text { Nevis, Saudi Arabia, Sri Lanka, Suriname, Sweden, Tunisia, } \\
\text { Turkey, }\end{array}$ & 0.03 & 2.89 & Convergence \\
\hline Club 4 & Cabo Verde, Nigeria, Saint Vincent and the Grenadines, & 0.13 & 3.04 & Convergence \\
\hline Club 5 & Seychelles, Switzerland & 3.05 & 4.19 & Convergence \\
\hline Group & Paraguay & --- & --- & \\
\hline
\end{tabular}


Figures

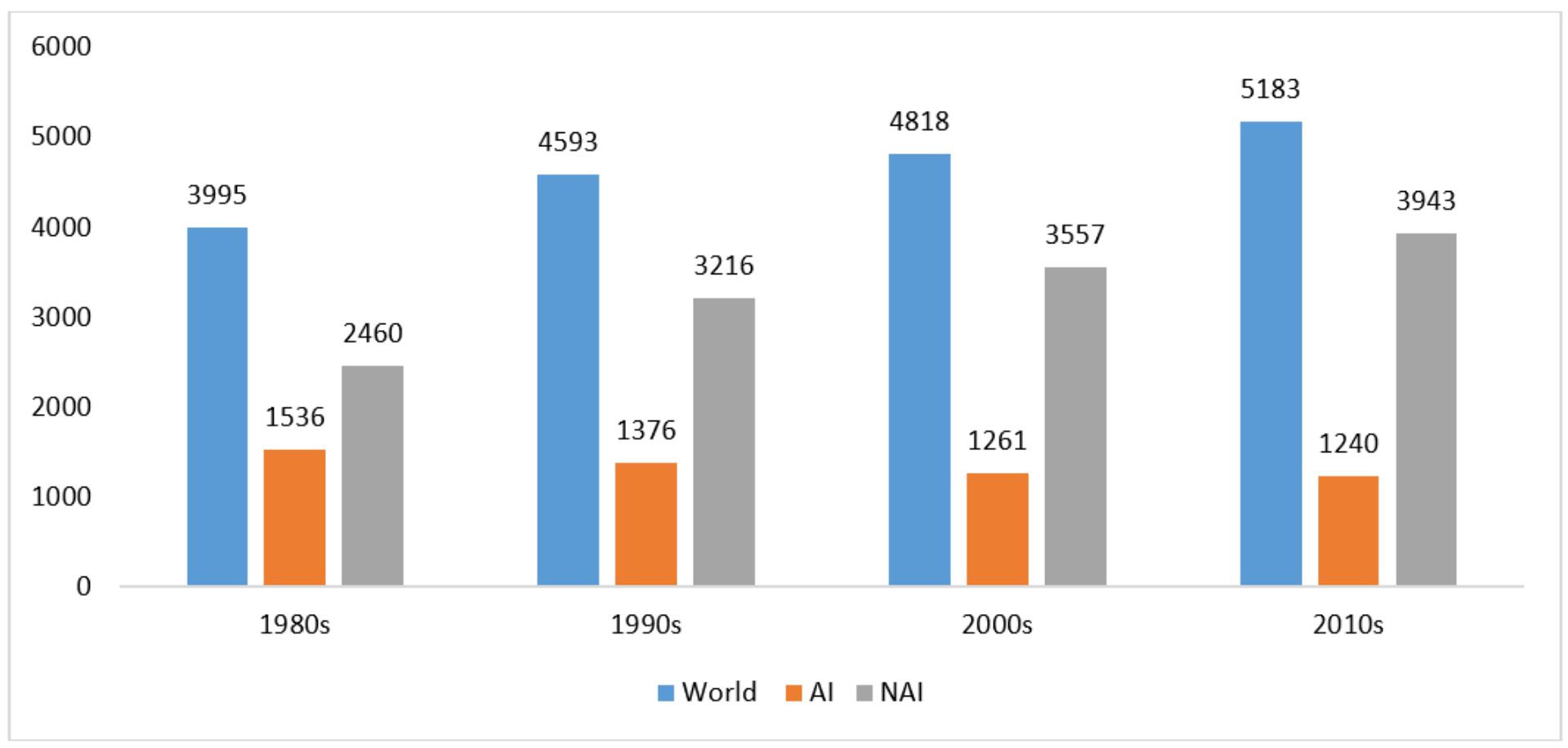

\section{Figure 1}

Plot the decadal GHGs emission. Note: Author's plot based on the FAOSTAT database

\section{Regional Contributions}

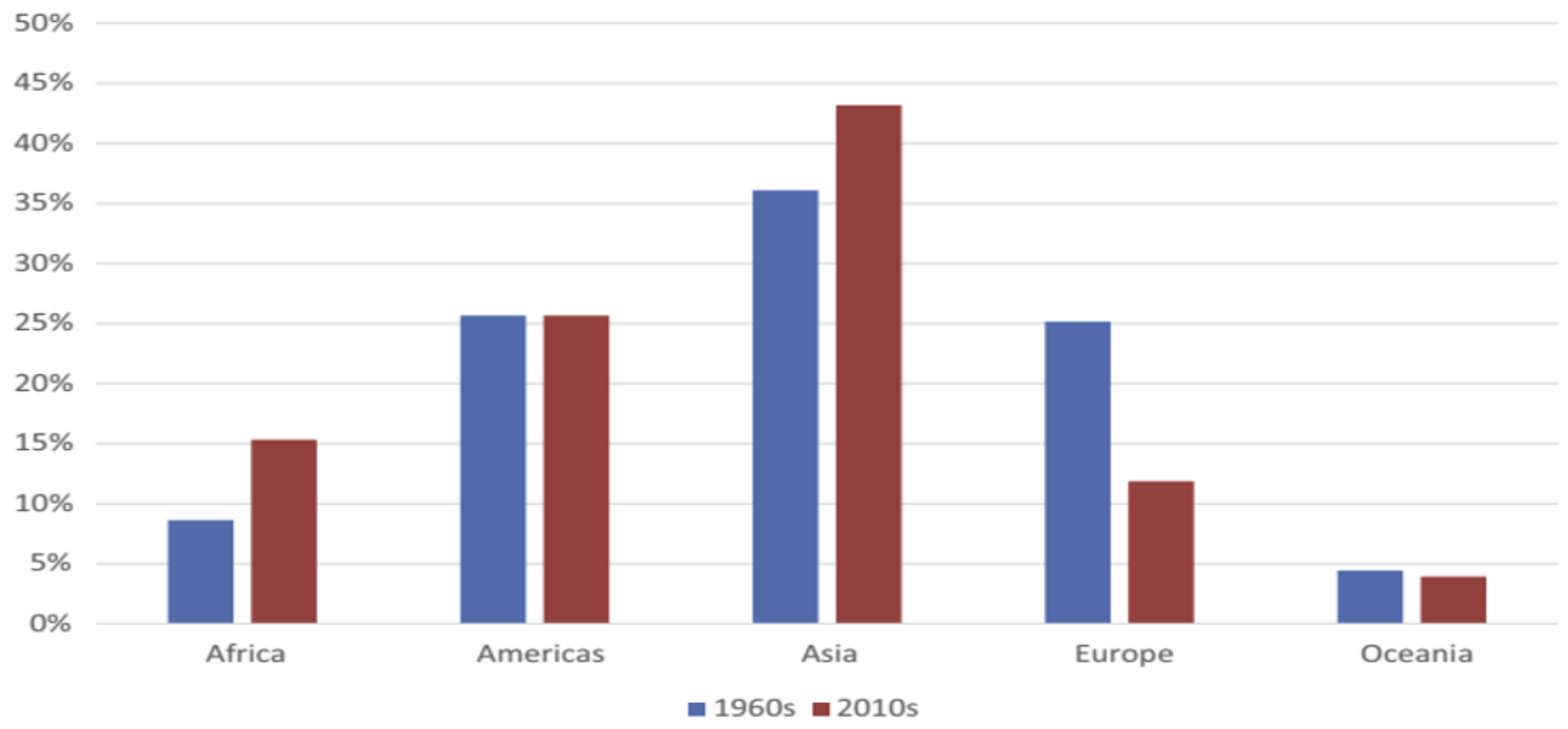

Figure 2 
Decadal averages, regarding the period 1961-2016, of the percent (\%) contributions of regional emissions to global GHGs emissions from agriculture, shown for two decades: 1960s and 2010s. Source: FAOSTAT database (FAO, 2018), domain: Emissions-Agriculture. More details of the same can be found in Tubiello, (2019).

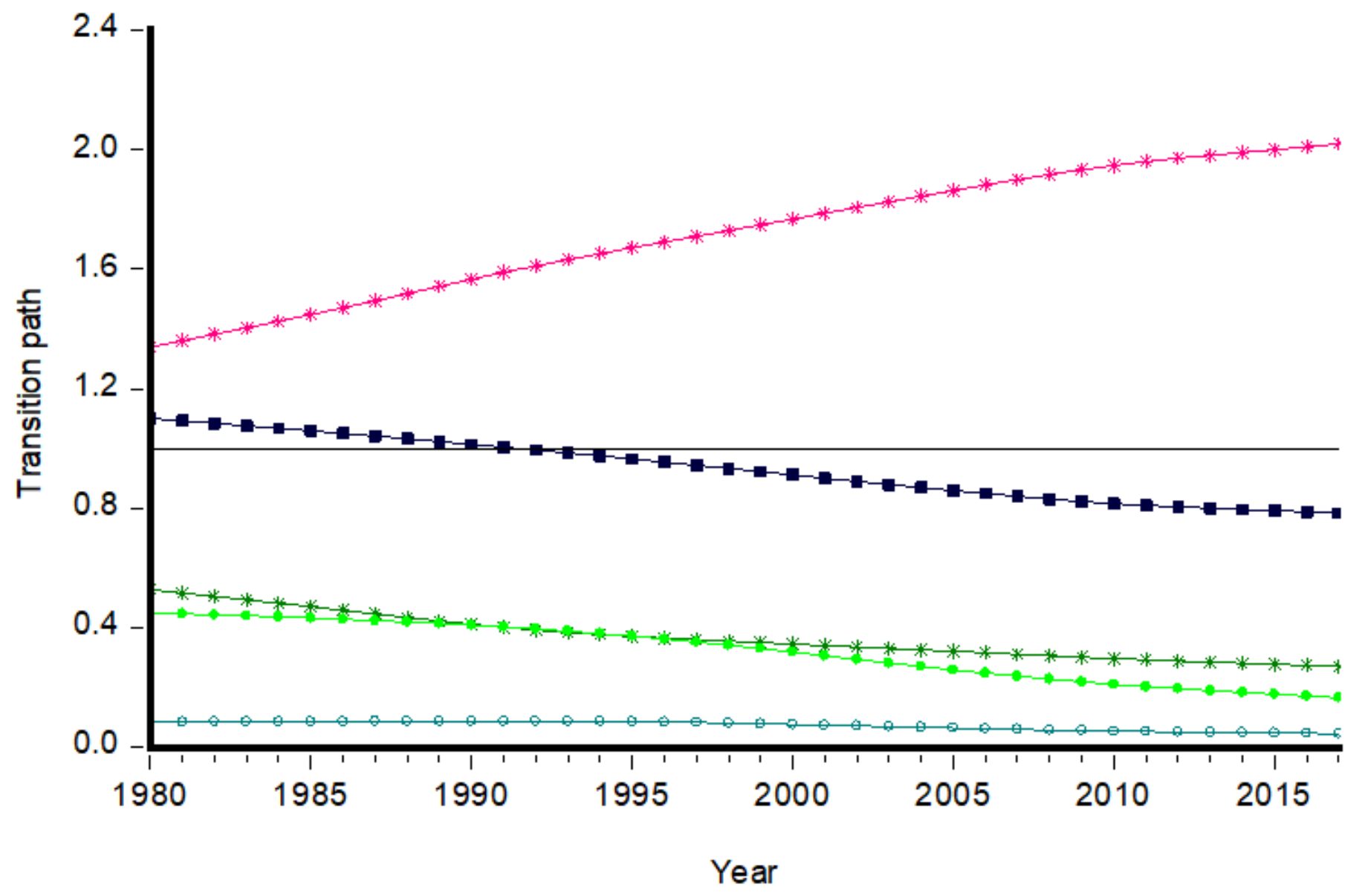

\section{Figure 3}

This figure indicates the transition paths of GHG emissions across the clubs. We observed that GHG emission level of Clubs 3, 4 and 5 countries have been decreasing over the years. These countries can be the policy guiding countries for Club 1 countries where GHG emission level is found to be relatively high (or above the stability line). 